\title{
Respiratory status and allergy nine to 10 years after acute bronchiolitis
}

\author{
V Noble, M Murray, M S C Webb, J Alexander, A S Swarbrick, A D Milner
}

\begin{abstract}
In order to evaluate further the relationship between acute bronchiolitis in infancy and subsequent respiratory problems, children prospectively followed up from the time of their admission to hospital were reviewed along with a group of matched controls recruited at the previous five and a half year assessment. Sixty one index children and 47 controls took part. The groups were well matched for age, height, parental smoking, and social class. Although the prevalence of respiratory symptoms had fallen when related to the previous review, there remained an excess of coughing (48 and $17 \%$ in index and control children respectively; odds ratio 4.02 ) and wheezing (34 and $13 \%$ in index and control children respectively; odds ratio 3.59 ). Bronchodilator therapy was used by $33 \%$ of index children compared with $3 \%$ of controls. Lung function tests revealed no significant differences in the measurements of lung growth-for example, forced vital capacity, functional residual capacity, and total lung capacity - but the index children had significant reductions in measurements of airways obstruction-for example, forced expiratory volume in one second, maximum expiratory flow at 75,50 and $25 \%$ of vital capacity, and airways resistance. Family history and personal skin tests showed no excess of atopy in the index group. This study supports the claim that the excess respiratory symptoms after acute bronchiolitis are not due to familial or personal susceptibility to atopy. (Arch Dis Child 1997;76:315-319)
\end{abstract}

Keywords: bronchiolitis; respiratory status; allergy

Department of Child Health, University Hospital, Nottingham V Noble

M Murray

M S C Webb

J Alexander

A S Swarbrick

A D Milner

Correspondence to: Professor A D Milner, Department of Paediatrics, St Thomas's Hospital,United Medical and Dental School, London SE1 7EH.

Accepted 30 September 1996 yeare likely to have recurrent subsequently. ${ }^{1-17}$ The prevalence of such symptoms may be as high as $75 \%$ in the subsequent two years, ${ }^{6}$ falling to $40-50 \%$ by 3 to 5 years of age. ${ }^{7}$ Ten years on, these children are reported to be at least twice as likely to have asthma symptoms as matched controls and have increased incidence of bronchial lability as measured by exercise or histamine challenge tests. ${ }^{4}$ Even those whose bronchiolitis is of insufficient severity to require hospital admission have an increased risk of recurrent wheez- ing attacks, which persists up to the age of 13 years. ${ }^{18}$ As a result, it has been estimated that acute bronchiolitis is responsible for at least $20 \%$ of wheezing attacks in preschool children. ${ }^{19}$

There remains, however, considerable dispute about the mechanisms behind the association. It has been claimed by some that infants requiring admission to hospital for bronchiolitis are those who are genetically predisposed to have subsequent asthma, either as a result of an atopy predisposition or a family history of recurrent wheezing attacks. ${ }^{2}{ }^{1314}$ In contrast, follow up studies by Pullan et $a l^{4}$ and by our own group ${ }^{20}$ have failed to find any such relationship. In the Pullan cohort ${ }^{4}$ the frequency of a family history of wheezing in the index cases was identical with that in the controls. In addition, those who had had bronchiolitis had significantly fewer positive skin tests to common allergens than the controls. Our prospective data also showed that five and a half years after the episode of acute bronchiolitis there was no evidence of an inherited predisposition to wheeze as defined by family history of atopy or wheezing. ${ }^{20}$

Other possible aetiological factors previously considered include large family size, ${ }^{4116}$ parental smoking, ${ }^{1161819}$ and breast feeding ${ }^{1121}$ Analysis of our five and a half year follow up data $^{20}$ using a stepwise logistic regressional model, including atopy, failed to identify any significant predictor of wheezing apart from the episode of bronchiolitis.

The aim of the present study was to review the children who had been prospectively followed up from the time of their admission to hospital with acute bronchiolitis along with their matched controls, who were recruited to the study at the five and a half year assessment once they were approximately 10 years old. In particular, we wished to investigate lung function in greater detail than was possible in the previous study, and repeat the stepwise logistic regression analysis on current symptoms in order to investigate the frequency, severity, and causes of respiratory problems nine to 10 years after acute bronchiolitis.

\section{Patients and methods}

PATIENTS

The original cohort consisted of 101 infants admitted to the children's wards of the University Hospital, Nottingham in the winter epidemics of bronchiolitis of 1979, 1980, and 1981.

The criterion for entry was the clinical diagnosis of acute bronchiolitis in a child who had 
had no previous similar illness. Clinical diagnosis required the presence of tachypnoea, hyperinflation, recession, and fine crepitations on auscultation recorded at some time during the admission. Many in addition had ronchi and difficulty with feeding.

The mean age at the time of admission was 113 (range 25-343) days. The 21 children recruited in 1979 were those who required nasogastric tubes, as these children took part in a study into the effects of acute bronchiolitis on the work of breathing. In the two subsequent years the only requirement was the need for admission. In the original cohort 54 were boys and 47 girls. Nasal secretions were obtained for RSV immunofluorescence in 86 . Of these, 57 $(66 \%)$ were positive.

These children were reviewed at three months and one, two, ${ }^{6}$ and three and a half ${ }^{7}$ years later. Five and a half years after their original admission with bronchiolitis, 73 were reviewed again..$^{20}$ At this stage, controls were recruited on a one for one basis. These children were selected by obtaining roll lists from the schools in the catchment area of the hospital and matching each index child in terms of birth date, sex, race, area, and history of maternal smoking. Those who had a history of admission to hospital for bronchiolitis or an illness suggestive of bronchiolitis requiring a visit to their general practitioner were excluded from the control group.

Approximately nine and a half years after the hospital admission, attempts were made to review all 146 of these children. Contact was established with 61 of the index cases and 47 of the controls.

Data were collected on age at assessment, weight, height (stadiometer), and history of lower respiratory tract symptoms over the previous year obtained from the mother. Data obtained at the previous reviews were used for the incidence of lower respiratory tract symptoms in earlier childhood rather than rely on parental memory.

LUNG FUNCTION TESTS

Peak flow (PEFR) was recorded using a Wright's peak flow meter. Forced vital capacity (FVC) and forced expiratory flow volume (FEV) measurements were obtained using an 8 litre dry spirometer (P K Morgan). The results were calculated using specially constructed software. They were corrected for body temperature and pressure, saturated with water, and related to sex and height using the normal data of Cotes. ${ }^{23}$ For each child the best of three blows was used after a period of training.

A 200 litre total body pressure plethysmograph was used to measure thoracic gas volume at functional residual capacity (FRC). At the end of each period of shutter closure the children were exhorted to breathe in to total lung capacity (TLC) and then breathe out fully so that TLC and residual capacity could also be calculated. The results were again related to height and sex using normal data. Airways resistance (Raw) was measured using standard techniques, ${ }^{24}$ and corrected for apparatus resistance and 50\% expected anatomical dead space.

Finally a histamine challenge was performed using the technique of Cockroft et $a l^{25}$ in which doubling concentrations of buffered histamine phosphate were inhaled for one minute commencing with $0.25 \mathrm{mg} / \mathrm{ml}$ and finishing either when the PEFR fell by more than $20 \%$ or a concentration of $8 \mathrm{mg} / \mathrm{ml}$ was reached. The results were plotted on semilog paper and the concentration producing a $20 \%$ fall in PEFR was determined.

Skin tests were performed using the epicutaneous prick test method ${ }^{26}$ with three Bencard solutions, cat fur, house dust mite, and B2 grass pollens, along with a positive (histamine) and a negative (saline) control. A weal diameter of at least $3 \mathrm{~mm}$ at 15 minutes was regarded as positive.

\section{STATISTICAL ANALYSIS}

Results were analysed using the $\chi^{2}$ test (with Yates's correction when $\mathrm{n}<100$ ), and the Fisher's exact test was used when the expected frequency for any cell was less than 5 . Where appropriate, odds ratios (ORs) with their 95\% confidence intervals were calculated. The unpaired $t$ test was used for continuous variables. In addition, the $95 \%$ confidence limits of the differences in lung function results between the index and control groups were calculated. The Mann-Whitney $U$ test was used for variables that were not normally distributed. The SPSS/PC statistical package was used to carry out a stepwise logistic regression to assess whether any relationship between bronchiolitis and current symptoms remained significant after other variables that have been claimed to have a confounding effect in previous reports were taken account of.

ETHICS

The study was approved by the ethics committee of the University Hospital, Nottingham. Informed written consent was obtained from all the children's parents.

\section{Results}

Eleven of the index and 25 of the control children were lost to follow up. Of these, nine index children and 21 controls could not be contacted despite three letters and phone calls. One of the index children and three of the controls did not wish to take any further part in the study, but one index and one control set of parents agreed to a home visit, so that information on current symptoms and status could be obtained. One control and one index family had moved away.

This left 61 index children and 47 controls (table 1). The five and a half year database ${ }^{20}$ was used to compare the relevant characteristics of those who took part in the follow up study and those who defaulted (table 2). There were no significant differences detected when sex, maternal smoking, first degree relatives with atopy, cough, wheeze, use of bronchodilator drugs, or results of skin tests at the time of 
Table 1 Clinical details and atopic status of index and control groups. Mean (SE) values are given for age and height

\begin{tabular}{llll}
\hline & Index & Controls & p Value \\
\hline No & 61 & 47 & - \\
Boys/girls (\% boys) & $26 / 35(43)$ & $27 / 20(57)$ & 0.13 \\
Age in years & $10.09(0.04)$ & $9.95(0.04)$ & 0.014 \\
Height in cm & $137.5(0.8)$ & $137.7(0.9)$ & 0.89 \\
Smoking mothers (\%) & $25(41)$ & $18(38)$ & 0.93 \\
Smoking fathers (\%) & $21(34)$ & $21(45)$ & 0.45 \\
Social class (\%) & & & \\
1 & 3.3 & 2.1 & \\
2 & 6.7 & 2.1 & \\
3 & 50.0 & 46.8 & \\
4 & 16.7 & 19.1 & \\
5 & 1.7 & 14.9 & \\
Unclassified & 21.7 & 14.9 & \\
Missing data & 1.6 & 0 & 0.14 \\
Atopic first degree relative (\%) & 55 & 42 & 0.64 \\
Atopic second degree relative (\%) & 58 & 49 & 0.92 \\
Skin test positive (\%) & 31 & 30 & \\
\hline
\end{tabular}

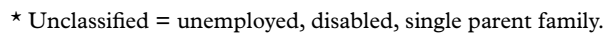

Table 2 Comparison of details on children who attended and those who failed to take part based on data obtained at the five and a half year review

\begin{tabular}{llllll}
\hline & \multicolumn{2}{l}{ Index } & & \multicolumn{2}{l}{ Controls } \\
\cline { 2 - 3 } \cline { 5 - 6 } & Yes & No & & Yes & No \\
\hline No & 61 & 12 & & 47 & 26 \\
Boys (\%) & 43 & 33 & & 57 & 42 \\
Smoking mothers (\%) & 60 & 83 & & 42 & 61 \\
Atopic first degree relative (\%) & 33 & 33 & & 25 & 27 \\
Cough (\%) & 61 & 58 & & 40 & 31 \\
Wheeze (\%) & 43 & 42 & & 15 & 15 \\
Use of bronchodilators (\%) & 33 & 33 & & 3 & 8 \\
Skin test positive (\%) & 28 & 36 & & 19 & 15 \\
\hline
\end{tabular}

Table 3 Respiratory symptoms in the index and control children

\begin{tabular}{lllll}
\hline & Index & Controls & $p$ Value & Odds ratio (95\% confidence interval) \\
\hline Cough (\%) & $29(47)$ & $8(17)$ & 0.002 & $4.02(2.05$ to 7.91$)$ \\
Wheeze (\%) & $21(34)$ & $6(13)$ & 0.018 & $3.59(1.31$ to 9.81$)$ \\
Asthma (\%) & $24(39)$ & $6(13)$ & 0.004 & $4.43(1.63$ to 12.0$)$ \\
\hline
\end{tabular}

Table 4 Results of lung function tests in index and control children; results are \% predicted for height and sex (SE)

\begin{tabular}{|c|c|c|c|c|}
\hline & Index & Controls & $p$ Value & $\begin{array}{l}95 \% \text { confidence intervals of } \\
\text { differences }\end{array}$ \\
\hline PEFR & $93.2(1.6)$ & $102.0(1.7)$ & 0.0003 & 4.1 to 13.4 \\
\hline FVC & $88.9(1.5)$ & $92.0(1.7)$ & 0.17 & -1.4 to 7.5 \\
\hline $\mathrm{FEV}_{0.75}$ & $88.6(1.5)$ & $94.0(1.6)$ & 0.01 & 0.99 to 9.8 \\
\hline $\mathrm{FEV}_{10}$ & $91.0(1.5)$ & $96.1(1.7)$ & 0.03 & 0.53 to 9.56 \\
\hline $\mathrm{MEF}_{75}$ & $90.1(2.0)$ & $97.6(2.2)$ & 0.014 & 1.55 to 13.45 \\
\hline $\mathrm{MEF}_{50}$ & $85.5(2.5)$ & $100.4(3.3)$ & 0.0004 & 6.75 to 23.1 \\
\hline $\mathrm{MEF}_{25}$ & $85.5(3.1)$ & $95.2(4.0)$ & 0.048 & 0.078 to 20.04 \\
\hline FRC & $99.2(3.5)$ & $102.9(3.7)$ & 0.47 & -6.5 to 13.8 \\
\hline TLC & $88.0(1.8)$ & $91.6(1.7)$ & 0.15 & -1.37 to 8.69 \\
\hline RV & $120.2(5.6)$ & $122.2(6.5)$ & 0.82 & -15.0 to 18.9 \\
\hline $\operatorname{Raw}\left(\mathrm{cmH}_{2} \mathrm{O} / \mathrm{l} / \mathrm{s}\right)$ & $2.87(0.12)$ & $2.35(0.12)$ & 0.002 & -0.85 to -0.21 \\
\hline $\mathrm{SGaw}\left(\mathrm{cmH}_{2} \mathrm{O} / 1 / \mathrm{s}\right)$ & $0.31(0.02)$ & $0.34(0.02)$ & 0.13 & -0.01 to 0.081 \\
\hline $\mathrm{PC}_{20}(\mathrm{~g} / \mathrm{l})$ & $5.41(0.40)$ & $6.1(0.44)$ & 0.25 & -0.49 to 1.86 \\
\hline
\end{tabular}

$\mathrm{FVC}=$ forced vital capacity; $\mathrm{FEV}_{0.75}$ and ${ }_{1.0}=$ forced expiratory volume in 0.75 seconds and one second respectively; $\mathrm{MEF}_{0.75}, 0.5$ and ${ }_{0.25}=$ maximum expiratory flow at $75,50,25 \%$ of vital capacity respectively; SGaw $=$ specific conductance; $\mathrm{PC}_{20}=$ concentration of histamine producing a $20 \%$ fall in PEFR. $(\mathrm{p}=0.14)$. There were also no significant differences in the number of older or younger siblings between the two groups.

Significantly more episodes of coughing and wheezing were reported for the index children by their parents, with ORs of 4.02 and 3.59 respectively (table 3 ). Twenty $(33 \%)$ of the index children and only two $(3 \%)$ of the controls were receiving at least intermittent bronchodilator therapy, and seven of the index children were also on prophylactic therapy (four on inhaled topical steroids and three on sodium cromoglycate). A presumptive diagnosis of asthma based on the history of current respiratory symptoms and prescribed drugs was made by one of the authors (VN) on 39\% of the index children compared with only $13 \%$ of the controls (OR 4.43).

Although there was a tendency for measurements of static lung volume measurements (FRC, TLC, and residual capacity) to be lower in the index group, none of these reached statistical significance, and none had $95 \%$ confidence limits for the differences between the means which crossed zero (table 4). A similar pattern emerged for FVC. All measurements expected to be affected by changes in airway obstruction did, however, show statistically significant differences between the groups, with a greater than $5 \%$ reduction in $\mathrm{FEV}_{0.75}$ and $\mathrm{FEV}_{1.0}$, and reductions in expiratory flow measurements of up to $15 \%$ when the index children were compared with the controls. For all these measurements the $95 \%$ confidence limits of the differences did not cross zero. The index children also had significantly higher Raw values but the specific conductance results only showed a non-significant trend with higher values in the control children.

Although there was a trend towards increased sensitivity to inhaled histamine in the group that had suffered bronchiolitis, this also failed to reach significance.

There were no significant effects of maternal or paternal smoking on wheeze ( $p=0.53$ and 0.88 respectively) when all the children were included, or on wheeze or cough when the index children were considered alone $(p=0.22$ and 0.43 , and $\mathrm{p}=0.31$ and 0.86 respectively).

Some $31 \%$ of the index children had at least one positive skin test compared with $30 \%$ of the controls (table 1). The presence of a positive skin test just failed to be significantly related to coughing in the index group ( $\mathrm{p}=$ 0.057). There was an even weaker relationship between wheezing or diagnosis of asthma and positive skin tests $(\mathrm{p}=0.137$ and 0.44 respectively). In the control children, the pattern was different with a significant relationship between positive skin test and wheezing ( $\mathrm{p}=$ $0.031)$ but not coughing ( $\mathrm{p}=0.21$ ) or diagnosis of asthma $(p=0.31)$.

The percentages of index children with first degree or second degree relatives with asthma and/or eczema were 55 and 58 respectively (table 1). The respective figures for the control group were $42 \%$ and $49 \%$. None of these differences were significant, and no significant relationship could be demonstrated between positive family history and presence of cough, 
wheeze, or diagnosis of asthma in the index children.

When parental smoking, number of siblings, primary and secondary family history of atopy (asthma, hay fever, and eczema) were included within the group (bronchiolitis or control) in the stepwise logistic regression model, the only variable found to be significantly related to wheezing, coughing, or diagnosis of asthma was the history of bronchiolitis.

\section{Discussion}

The main findings of this study are that nine to 10 years after an episode of acute bronchiolitis of sufficient severity to require hospital admission, the prevalence of wheezing was over three times that of the control group (OR 4.02). The ORs for coughing and diagnosis of asthma were similarly raised at 3.59 and 4.43 respectively. The lung function data indicated that overall lung growth, as measured by FVC, FRC, and TLC, was not significantly affected. In contrast, lung function measurements identifying abnormal airways obstruction, PEFR, $\mathrm{FEV}_{1.0},{ }_{0.75}$, maximum expiratory flow rates derived from the flow/volume curve and Raw measured plethysmographically, were all significantly worse in the index group than the controls. There was no evidence that the children who had had bronchiolitis came from families with an increased incidence of wheezing attacks or history of atopic tendency. Skin tests also failed to show that the index group had an increased incidence of personal atopy which might otherwise explain the tendency to cough and wheeze. These findings support those of Pullan and Hey. ${ }^{4}$

This study has both the strengths and weaknesses of many long term follow up projects. As the children were recruited during the acute admission, it is possible to be much more confident on the initial diagnosis. The requirement for the presence of fine crepitations in the absence of pneumonia or heart failure probably excluded a number of babies who did have acute bronchiolitis but ensured that children presenting with acute asthma were not included. A number of studies reaching very different conclusions on the importance of positive family and personal history of atopy are based on very different diagnostic criteria, including all first episodes of wheezing in the first one to two years of life. It is not surprising that children recruited in this way show positive associations with atopy. The main weakness is the loss of children to follow up in the index group and to a greater extent the control group. Considerable care had been taken to ensure that the control children recruited at the time of the five and a half year assessment matched the index children for variables likely to influence the frequency of respiratory symptoms. These included birth date, sex, race, maternal smoking, and domicilary area. This was achieved with a considerable degree of success. In addition, the groups were well matched for breast feeding and social class. The only significant difference emerging was an excess of older siblings in the index group. As only $84 \%$ of the index group and
$64 \%$ of the controls could be contacted and agreed to take part in this nine and a half year assessment, it was obviously of critical importance to evaluate whether the remaining children were well matched for demographic data. Serendipitously this turned out to be the case. The only significant difference was that the index group were a few days older on average. There was an excess of girls in the index group and of boys in the control, but this did not reach statistical significance. As the prevalence of respiratory symptoms tends to be lower in girls than boys, this may have weakened the association between bronchiolitis and subsequent symptoms but will not have had a confounding effect. Not surprisingly, the prevalence of smoking was very similar in the two groups as this was one of the matching factors, as was the social class distribution.

The prevalence of wheeze in the index group had fallen from $43 \%$ at the five and a half year assessment to $34 \%$, while in the control group the frequency was essentially unchanged at 15 and $13 \%$ respectively. There was a reduction in the prevalence of cough in both the index children (from 61 to $47 \%$ ) and in the controls (from 40 to $17 \%$ ). It could be claimed that the diagnosis of asthma was subjective and could be affected by bias but it is unlikely that the gross differences in antiasthma therapy were due to factors other than excess of respiratory symptoms in the index group to any significant extent.

At the five and a half year assessment there was a significant excess of positive skin tests in the index group, ${ }^{20}$ although no relationship between skin test positivity and respiratory symptoms was observed. In the current assessment no such difference emerged.

In this assessment there was no detectable effect of maternal smoking on respiratory symptoms in either the combined groups or in the index children alone. Although some investigators have been able to demonstrate an effect this late in childhood, ${ }^{18}$ the majority of studies have been largely negative, ${ }^{27}$ very different from the close relationship seen in the first five years of life. ${ }^{27}$

Although we were able to find evidence that the index children had poorer airway function than the controls, there was very little difference in the histamine challenge results, unlike the pattern found at the five and a half year assessment.

If, as we claim, the excess of respiratory symptoms and abnormal lung function is not due to an inherited tendency to wheeze or to atopy, other causal associations must be sought. It is possible that infection with RSV is directly responsible for ongoing airway inflammation. Although there is an outpouring of inflammatory secretions with a predominance of neutrophils, ${ }^{28}$ it seems unlikely that this can be responsible for an excess of symptoms nearly 10 years later.

There has also been considerable interest in the claim that RSV infection stimulates the local production of RSV specific IgE within the airway, and that in the short term there is a direct relationship between the levels of these 
antibodies and the subsequent history of wheezing. ${ }^{29}$ Eight years later, although there remained an association between the development of these antibodies and respiratory symptoms, this did not reach statistical significance. ${ }^{30}$ The inability of other groups to replicate these findings has left some doubt about their significance, although there is increasing evidence that $\operatorname{IgE}$ may be released into the airway secretions during acute bronchiolitis $^{31}$ or appear in the blood. ${ }^{15}$

A further recent observation from Perth, Australia $^{32}$ that infants requiring admission to hospital for acute bronchiolitis are more likely to have suboptimal lung function at 1 month of age - that is, before the development of any respiratory symptoms - raises the possibility that the bronchiolitis is identifying those infants who have poorly developed airways and who are at increased risk of developing recurrent attacks of coughing and wheezing in response to upper airway tract infections. Whether such a mechanism could be implicated for symptoms 10 years later seems less likely.

In conclusion, we have found an excess of respiratory symptoms and lung function abnormalities compatible with an increased prevalence of asthma persisting for at least nine years after episides of well documented acute bronchiolitis. The explanation for this remains to be evaluated, but there is no evidence from this prospective study that the excess is due to a personal or familial history of asthma or atopy.

We gratefully acknowledge financial help from the Children Nationwide Medical Research Fund and from the National Asthma Campaign.

1 Sim DG, Downham MAP, Gardner PS, Webb JKG Weightman D. Study of 8 year old children with a history of respiratory syncytial virus bronchiolitis in infancy. $B M^{\mathcal{F}}$ 1978;i:11-4

2 Duiverman EJ, Neijens HJ, Van Strik R, Affourht MJ, Kerrebijn KF. Lung function and bronchial responsiveness in children who had infantile bronchiolitis. Pediatr Pulmonol 1987;3:38-44.

3 Gurwitz D, Levison $H$. Increased incidence of bronchial reactivity in children with a history of bronchiolitis. $\mathcal{F}$ Pediatr 1981;98:551-5.

4 Pullan C, Hey E. Wheezing, asthma and pulmonary dysfunction 10 years after infection with respiratory syncytial virus in infancy. BMF 1982;284:1665-9.

5 Sly PN, Hibbert ME. Childhood asthma following hospitalisation with acute viral bronchiolitis in infancy. Pediatr Pulmonol 1989;7:153-8.

6 Henry RL, Hodges IGC, Milner AD, Stokes GM. Respiratory problems 2 years after acute bronchiolitis in infancy. tory problems 2 years after act
Arch Dis Child 1983;58:713-6.

7 Webb MSC, Henry RL, Milner AD, Stokes GM, Swarbrick AS. Continuing respiratory problems three and a half years after acute viral bronchiolitis. Arch Dis Child 1985;60:10647.

8 Eisen AH, Bacal JL. The relationship of acute bronchiolitis to bronchial asthma: a 4-14 year follow up. Pediatrics 1963; 31:859-61.
9 Rooney JC, Williams HE. The relationship between proved viral bronchiolitis and subsequent wheezing. I Pediatr 1971;79:744-7.

10 Twiggs JT, Larsen LA, O'Connell ES, Illstrup DM. Respiratory syncytial virus infection. Clin Pediatr (Phila) 1981;10:187-90.

11 Mok JYQ, Simpson H. Outcome of acute lower respiratory infection in infants. BMF 1982;285:33-7.

12 Zweiman B, Schoenwetter WF, Paooano JE, Tempest B, Hildreth EA. Patterns of allergic respiratory disease in chilHildreth EA. Patterns of allergic respiratory disease in chil-
dren with a past history of bronchiolitis. 7 Allergy Clin Immunol 1971;48:283-9.

13 Laing I, Riedel F, Yap PL, Simpson H. Atopy predisposing to acute bronchiolitis during an epidemic of respiratory syncytial virus. $B M \mathcal{F} 1982 ; 284: 1070-2$.

14 Carlson KH, Larsen S, Orstavik I. Acute bronchiolitis in infancy. The relationship to later recurrent obstructive airways disease. European Fournal of Respiratory Disease 1987; 70:86-92.

15 Sigurs N, Bjarnason R, Sigurberbsson F, Kjellman B, Bjorksten $\mathrm{B}$. Asthma and immunoglobulin $\mathrm{E}$ antibodies after respiratory syncytial virus bronchiolitis: a prospective cohort study with matched controls. Pediatrics 1995;95: 500-5.

16 Wittig HJ, Cranford NJ, Glaser J. The relationship between bronchiolitis and childhood asthma. A folllow-up study of 100 cases of bronchiolitis in infancy. $\mathcal{F}$ Allergy 1959;30:1923.

17 Kattan M, Keens TG, Lapierre JG, Levison H, Bryan AC, Reilly BJ. Pulmonary function abnormalities in symptom free children after bronchiolitis. Pediatrics 1977;59:683-8.

18 McConnochie KM, Roghmann KJ. Wheezing at 8 and 13 years; changing importance of bronchiolitis and passive smoking. Pediatr Pulmonol 1989;6:138-46.

19 Hall CB, Hall W, Gala CL, MaGill FB, Leddy JP. Long-term prospective study in children after respiratory syncytial virus infection. 7 Pediatr 1984;105:358-64.

20 Murray M, Webb MS, O'Callaghan C, Swarbrick AS, Milner AD. Respiratory status and allergy after bronchiolitis. Arch Dis Child 1992;67:482-7.

21 Rylander E, Erikson M, Freyschuss U. Risk factors for occasional and recurrent wheezing after RSV infection in infancy. Acta Paediatr Scand 1988;77:711-5.

22 Carlsen K, Larsen S, Bjerve O, Leegaard J. Acute bronchiolitis: predisposing factors and characterisation of infants at risk. Pediatr Pulmonol 1987;3:153-60.

23 Cotes JE. Lung function at different stages in life, including reference values. In: Cotes JE, ed. Lung function. Oxford: Blackwell Scientific Publications, 1975: 340-53.

24 Cogswell JJ, Hull D, Milner AD, Norman AP, Taylor B. Lung function in childhood. III. Measurement of airflow resistance in healthy children. British Fournal of Diseases of the Chest 1975;69:177-87.

25 Cockcroft DW, Killian DN, Mellon JJA, Hargreave FE. Bronchial reactivity to histamine: a method and clinical survey. Clin Allergy 1977;7:235-43.

26 Tipton WR. Evaluation of skin testing in the diagnosis of IgE-mediated disease. Pediatr Clin North Am 1983;30:78593.

27 Witorsch RJ. Parental smoking and respiratory health and pulmonary function in children: a review of the literature and suggestions for future research. In: Ecobichon DJ, ed. Environmental tobacco smoke. Lexington, Massachusetts: Lexington Books, 1990: 205-26.

28 Everard ML, Swarbrick A, Wightham M, et al. Analysis of cells obtained by bronchial lavage of infants with respiratory syncytial virus infection. Arch Dis Child 1994;71:428-32.

29 Welliver RC, Sun M, Rinaldo D, Ogra PL. Predictive value of respiratory syncytial virus-specific IgE responses for recurrent wheezing following bronchiolitis. F Pediatr 1986; 109:776-80.

30 Welliver CR, Duffy L. The relationship of RSV-specific immunoglobulin $\mathrm{E}$ antibody reponses in infancy, recurrent wheezing and pulmonary dysfunction at age $7-8$ years. Pediatr Pulmonol 1993;15:19-27.

31 Everard ML, Fox G, Walls AF, et al. Tryptase and IgE concentrations in the respiratory tract of infants with acute bronchiolitis. Arch Dis Child 1995;72:64-9.

32 Young S, O'Keeffe PT, Arnott J, Landau LI. Lung function, airways responsiveness, and respiratory symptoms befor and after bronchiolitis. Arch Dis Child 1995;72:16-24. 